\title{
The Effects of a Major Forcing Function, Wave Energy, on a Coral Reef Ecosystem
}

\author{
R. H. Bradbury ${ }^{1}$ and P. C. Young ${ }^{2}$ \\ ${ }^{1}$ Australian Institute of Marine Science, PMB No. 3, Townsville MSO, Qld. 4810, Australia \\ ${ }^{2}$ Division of Fisheries Research, CSIRO Marine Laboratories, P.O.B. 21, Cronulla, NSW 2230, Australia
}

\begin{abstract}
Interrelationships between major biotic and abiotic components of a coral reef ecosystem and one of its major forcing functions were studied along a reef flat transect at Heron Island, Great Barrier Reef. The ecosystem components were the topological complexitiy of the reef (reef structure), and the community structure of corals and fish. The forcing function was wave energy. Multivariate techniques were used to establish the pattern of relationships among replicate samples of each of the components. The results show that reef structure and coral community structure each respond substantially but independently to the forcing function. The reef structure is a simple and direct consequence of wave energy; but coral community structure and, to a greater extent, fish community structure are complex, indirect and non-linear consequences of wave energy. It is concluded that the forcing function enters the system through at least 2 independent paths and that, as it penetrates, its influence becomes attenuated as well as baroque.
\end{abstract}

\section{INTRODUCTION}

A coral reef may be idealized as an ecosystem acted on by forcing functions. That is to say, the various biotic and abiotic components of a coral reef, as well as interacting among themselves, are also subject to driving forces which originate outside the system itself and are not under its control. The realization of this concept for a particular coral reef is fraught with difficulty since the biotic components of the system are extremely complex, as are their interactions among themselves and with their abiotic components. The forcing functions are also complex on coral reefs, since they are often confounded and their effects may propagate through the system.

The aim of this study is to integrate these three facets of coral reef ecology - the biotic and abiotic components of the ecosystem and its forcing functions - in order to understand the ways in which coral reefs work. Tactically, however, our sights must be lowered by the complexities just mentioned. We chose several discrete ecosystem components which we felt were important, and we resolved their complexity using multivariate techniques. We then chose to study these components in an area of the reef where the major forcing functions were not confounded, and where one forcing function clearly dominated all others. Thus our aim is pared to the realistic goal of understanding the ways in which selected biotic and abiotic components of a coral reef ecosystem interact and are affected by a major forcing function.

\section{THE STUDY AREA}

Heron Island Reef $\left(23^{\circ} 27^{\prime} \mathrm{S}, 151^{\circ} 55^{\prime} \mathrm{E}\right)$ is in the Capricorn Group near the southern end of the Great Barrier Reef. It is an elongated reef about $11 \mathrm{~km}$ long on its east-west axis and $5 \mathrm{~km}$ wide at its eastern end. Heron Island is a small vegetated sand cay $(800 \mathrm{~m} \times 300 \mathrm{~m})$ at its western end. The northern side of Heron Island Reef is exposed to the full force of cyclonic winds that occur every few years, usually during the summer months. To the south, however, it is sheltered by the adjacent Wistari Reef from the effects of the Southeast Trade winds which prevail during the winter months (Flood, 1974).

The deposition and form of crest-derived sediments across the Reef reflect these two dramatically different sources of wind generated wave energy (Maxwell et al., 1964). In particular, a transect passing in a northerly direction from the relatively sheltered south- 
western edge of the Reef to its exposed northern edge encompasses the two extremes of wave energy on this reef.

The manifest changes in wave energy across this transect provide a good opportunity to explore the ways in which a major forcing function interacts with an ecosystem. The following factors need to be allowed for if this opportunity is to be fully exploited:

(1) Reef communities are affected by several other major environmental factors, the most important of which is light level (Chappell, 1980). Light level and wave energy are usually confounded on reef slope gradients, but on reef crests and flats, and in shallow lagoons, illumination varies little, so that wave energy is the major forcing function. In order to partition these effects the study was restricted to these areas.

(2) The environmental gradient in wave energy across the reef flat is not a gradient in the strict sense of Pielou (1977) since the level of wave energy does not fall monotonically across the transect and the two extremes of wave energy are separated in time. The wave energy decays towards the middle of the transect from both northern and southern sides of the reef, so that the gradient may be considered reflected about the middle of the transect. With this proviso, Pielou's (1977) comments about the enormous utility of gradients for ecological study apply. That the two sorts of wave energy are temporally as well as spatially separated in their effects is not a major problem either. Major components of the reef ecosystem, such as the main reef framebuilders, the corals, are long lived relative to the time constants of the forcing functions (Grassle, 1973), so they are able to integrate these effects through time. Thus the structure of the reef communities reflects their integrated response through time to the forcing function under study.

(3) The effects of major forcing functions, such as wave energy, may propagate through the ecosystem and impinge on parts of the system far removed from the original effect. In particular, the architecture of the reef, which is itself an amalgam of living and nonliving attributes, is affected by the wave energy regime (Stoddart, 1969; Chappell, 1980); and a major component of the ecosystem, the fish community, is affected by the reef architecture (Gladfelter and Gladfelter, 1978; Luckhurst and Luckhurst, 1978; Talbot et al., 1978).

In order to translate these ideas into a field sampling program we established a transect about $1 \mathrm{~km}$ to the east of the cay. It passed from the sheltered southwestern reef crest across the reef flat and shallow lagoon in a northerly direction to the exposed northern reef crest as shown in Fig. 1. Forty-five sites were established at $50 \mathrm{~m}$ intervals from crest to crest and their levels relative to each other were measured.
The wave energy characteristics across the transect were reflected in the relative site levels which provide an efficient index of wave energy integrated through time. The general pattern (Fig. 1) is of a high crest with a depression behind followed by a rising level across a reef flat declining into the lagoon. On the northern edge, the crest is higher and wider, the depression behind deeper and the reef flat higher and wider than the southern edge because of the higher wave energy regime (Maxwell et al., 1964). The levels also allow'a subjective classification of the reef flat into zones (Table 1) whose names we will use below for convenience.

The transect thus provides a clear expression of a major forcing function. Our methodological strategy then became:

(1) to describe the topographic structure of the substrate, a major abiotic component of the system ('reef structure') in relation to the gradient;

(2) to describe the community structure of the corals, the main architectural components of the reef (coral

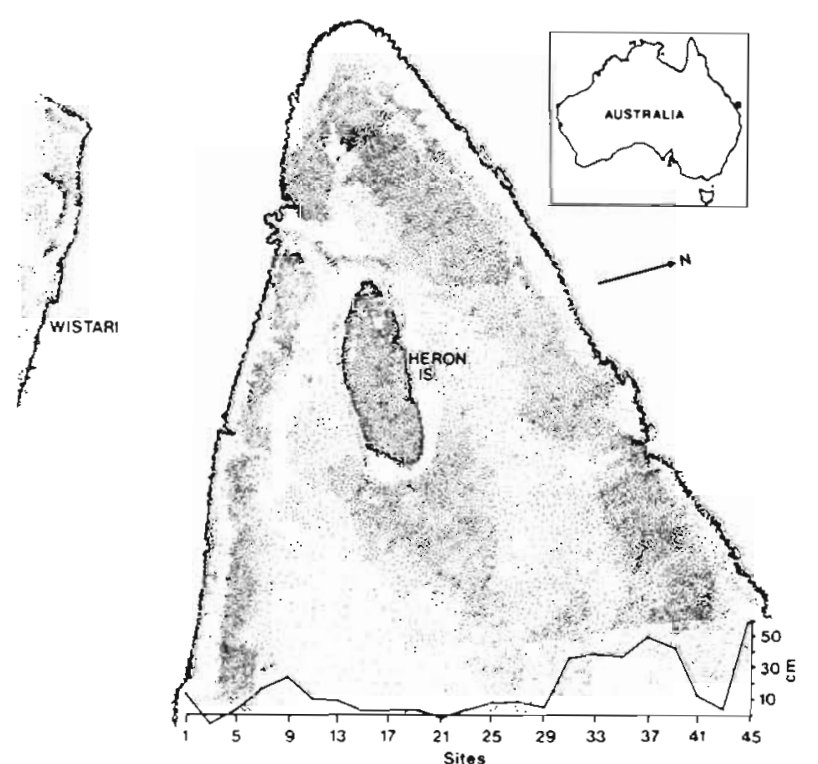

Fig. 1. Heron Island Reef. Shown are transect, sites and levels

Table 1. Subjective names of zones

\begin{tabular}{|rll|}
\hline $\begin{array}{c}\text { Approximate } \\
\text { span of sites }\end{array}$ & \multicolumn{1}{c}{ Name of zone } & Abbreviation \\
\hline 1 & South Crest & SC \\
$2-6$ & South Outer Reef Flat & SORF \\
$7-12$ & South Inner Reef Flat & SIRF \\
$13-25$ & Lagoon & L \\
$26-30$ & Pocillopora Zone & PZ \\
$31-38$ & North Inner Reef Flat & NIRF \\
$39-43$ & North Outer Reef Flat & NORF \\
$44-45$ & North Crest & NC \\
& & \\
\hline
\end{tabular}


community structure') in relation to the gradient and also to the reef structure;

(3) to describe the community structure of the fish, another major biotic component of the system ('fish community structure') in relation to the gradient, the reef structure and coral community structure.

\section{THE REEF STRUCTURE}

The substrate along the transect was subjectively divided into 9 structural types: viz: 5 living coral types (massive and submassive, thin, medium and thick ramose) and 4 non-living types (sand, rubble, consolidated and pavement). This classification encompassed the topographic complexity of the study area. The characteristics of the substrate types are given in Table 2 ).

The distribution of these substrate types was measured across the transect. The basic sampling unit was a line transect at right angles to the main transect. At each of the 45 sites, 3 replicate $10 \mathrm{~m}$ transects were made, the next replicate beginning where the previous one finished. Each sample consisted of a sequence of 50 records of the structural types recorded at $20 \mathrm{~cm}$ intervals. Each record consisted of the dominant (usually the only) type found inside a $10 \mathrm{~cm}$ diameter circle centred on the sampling point. Line transects such as these have been shown to be powerful sampling tools for coral reefs (Loya, 1978).

The 135 samples thus obtained were classified by the program CENPERC (Milne, 1976) using, as attributes, the frequencies of the 9 structural types in the samples. CENPERC is an agglomerative, polythetic program providing an information-statistic classification of frequency data. The particular algorithm used treats frequencies of all species as various states of a single multistate variable. The replicates showed statistically significant clustering at the 6-group level, using the test of Sandland and Young (1979a, b). Therefore it was considered that the replicates were sufficiently similar that they could be pooled to form 45 samples for further analysis.

The 45 sites were reclassified using the 9 structural types as attributes by the program CENPERC as before. A principal coordinate analysis, a type of ordination, was made on the intersite dissimilarity matrix, and the diagnostic program GOWECOR was run on the results of the ordination. All the taxonometric programs were from the CSIRO's library of pattern analysis programs as described by Milne (1976).

This classification (Fig. 2) extracts the traditional, but subjective, zones of reef crest, reef flat and lagoon (e. g. Rosen, 1971; Mergner and Scheer, 1974; Pichon, 1978) and also distinguishes between the occurrences of these features on the exposed northern and sheltered southern sides of the reef. The pattern of branching of the dendrogram also gives some clue to the relative importance of the wave energy intensity in differentiating northern and southern sides, from the wave energy attenuation towards the lagoon as a forcing function for zonation. At the 3-group level, the first few splits produce groups which reflect the zonation rather than the intensity effects of the forcing function - lagoon plus south inner reef flat sites, all other reef flat plus Pocillopora zone sites, and crest sites. At the 6 group level, these groups have been split largely into their north or south components. Subsequent splits confirm this trend but the pattern then becomes confusing as the idiosyncracies of individual sites begin to assert themselves

We conclude from the classification that the zonation is efficiently captured by the structural types, as is the difference between northern and southern sites, and that, of these two effects, the former is more important.

The ordination summarizes these patterns in a more succinct form. It was particularly efficient, the first 3 eigenvectors extracting $82 \%$ of the variance. This indicates that there is a high degree of structure in the distribution of the substrate types across the transect.

When the eigenvectors are plotted against the tran-

Table 2. Substrate types found in study area

\section{Type}

Description

\begin{tabular}{|ll|}
\hline \multicolumn{1}{|c|}{ Type } & Description \\
\hline LIVING & \\
Massive & Unbranched coral colonies with rounded regular surfaces \\
Submassive & Unbranched coral colonies with irregular surfaces or protuberances \\
Thin ramose & Branched coral colonies with main branches $<10 \mathrm{~mm}$ thick \\
Medium ramose & Branched coral colonies with main branches $10-20 \mathrm{~mm}$ thick \\
Thick ramose & Branched coral colonies with main branches $>20 \mathrm{~mm}$ thick \\
NON-LIVING & \\
Sand & Unconsolidated coral sand \\
Rubble & Unconsolidated coral fragments \\
Consolidated & Consolidated rubble and sand \\
Pavement & Smooth consolidated surface often with thin layer of fine sand on top \\
\hline
\end{tabular}

LIVING

Submassive

Medium ramose 


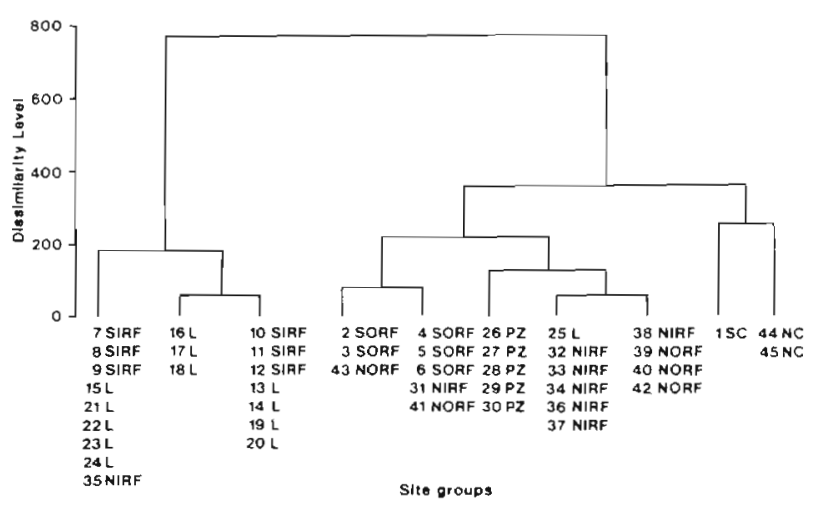

Fig. 2. Classification of reef structure. For abbreviations see Table 1
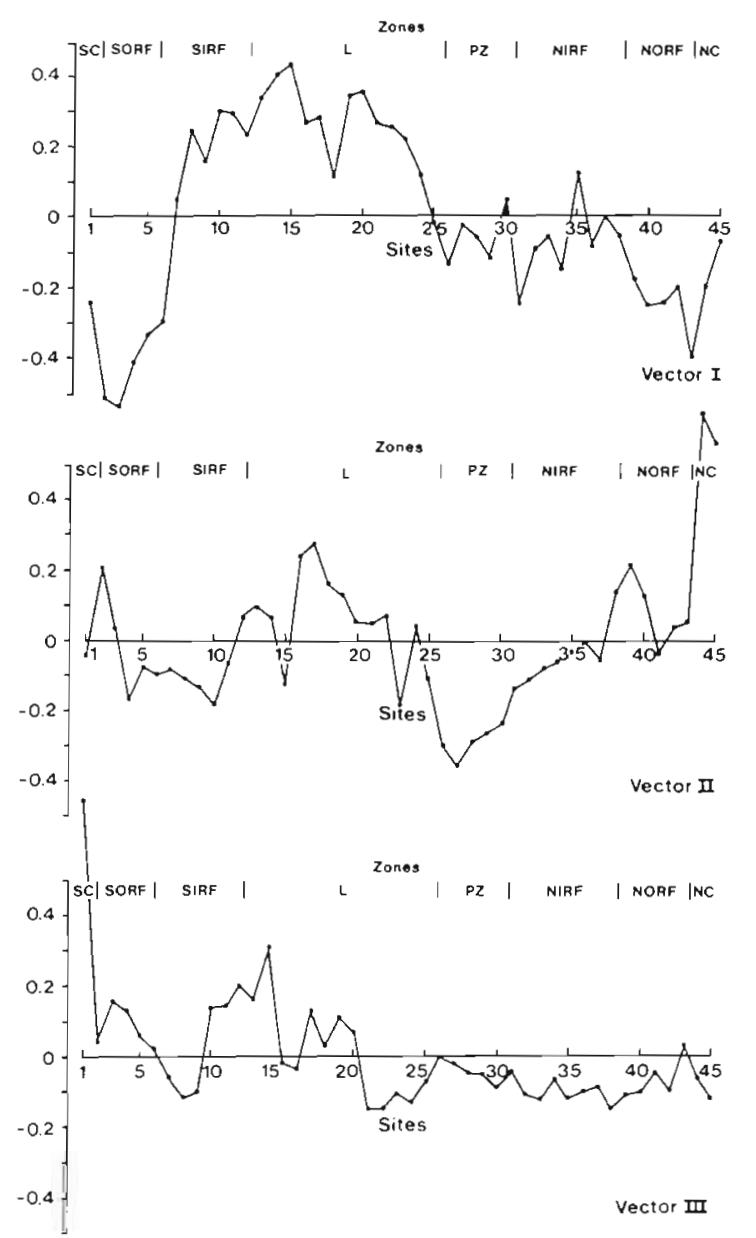

Fig. 3. Reef structure Vectors I, II and III plotted against transect. For abbreviations see Table 1

sect as shown in Fig. 3, the patterns extracted by the classification are seen clearly dissected into their component subpatterns. Each of the first 3 eigenvectors displays a gradient of dissimilarity passing from the reef crest sites towards the central lagoon sites, but they differ in the emphasis placed on the northern and southern crests vis a vis each other and the lagoon.
The first vector (accounting for $42 \%$ of the variance) discriminates between the 2 outer reef flats and crests on the one hand and the lagoon on the other with the extensive north inner reef flat and contiguous Pocillopora zone lying between in degree of dissimilarity. The second vector ( $25 \%$ of the variance) discriminates the outer part of the south outer reef flat, the lagoon, the inner part of the north outer reef flat, and particularly the north crest from the rest of the transect sites particularly the adjacent reef flats and Pocillopora zone. The third vector $(15 \%)$ discriminates between the southern reef crest, the lagoon and the rest of the transect.

Thus the ordination, too, captures a pattern of zonation of structural types which correlates well with incident wave energy as a major forcing function. More importantly, both analyses, but particularly the ordination, suggest a hierarchy of effects for this function. The most important effect, displayed clearly by Vector I, may be easily interpreted as the attenuation of wave energy (i e. as a forcing function for zonation). The second most important effect, as seen by Vectors II and III, is the intensity of the function causing qualitative differences between the 2 sides of the Reef. That these differences are also important is underscored by the fact that they require a vector each.

The diagnostic features of the reef structure are revealed by the GOWECOR analysis which measures the relative contributions of each of the 9 structural attributes to the ordination as correlation coefficients between the attribute and the vector. Diagnostic analyses such as this allow one to link the local patterns of individual attributes with the global patterns of all the samples taken as a whole. The results of the GOWECOR analysis are given in Table 3.

The first vector uses the distinction between sand and many of the other substrate types to achieve its discrimination between the lagoon and the outer reef flats and crests together. As such, it represents an integration of the process of coral decomposition to sand and its sorting by wave and current action, from the most active growing sites on the periphery of the reef towards the lagoon. The second distinguishes between rubble and thin ramose corals. This represents a quantitative north/south difference in response to wave action. The destruction of coral on the exposed north crest results in banks of rubble which are subsequently deposited on the inner part of the north outer reef flat. The more sheltered south crest reveals a different response (see below) and due to decreased wave energy, rubble is deposited on the outer part of the outer reef flat. Thin ramose corals occur in relatively sheltered water and have their greatest occurrence in areas least disturbed by wave energy. The presence of rubble and absence of thin ramose corals 
Table 3. Diagnostıc analysis: reef structure

\begin{tabular}{|c|c|c|c|c|c|}
\hline \multicolumn{2}{|l|}{1} & \multicolumn{2}{|c|}{ Vector } & \multicolumn{2}{|c|}{ III } \\
\hline Attribute & $\begin{array}{c}\text { Correlation } \\
\text { coefficient }\end{array}$ & Attribute & $\begin{array}{l}\text { Correlation } \\
\text { coefficient }\end{array}$ & Attribute & $\begin{array}{c}\text { Correlation } \\
\text { coefficient }\end{array}$ \\
\hline Sand & .89 & Rubble & .89 & Pavement & .88 \\
\hline Consolidated & -80 & Thin ramose & -.47 & Submassive & .56 \\
\hline Submassive & -67 & & & Massive & .40 \\
\hline Massive & -62 & & & & \\
\hline Thick ramose & -.56 & & & & \\
\hline Medium ramose & -.55 & & & & \\
\hline Pavement & 36 & & & & \\
\hline
\end{tabular}

in the lagoon is almost certainly due to factors unrelated to wave energy. The third vector emphasizes pavement and non-branched corals to discriminate the south reef crest from the rest of the transect. On the south crest, the wave action is not sufficiently intense to break up the coral morphology to create wave resistant massive and submassive colonies

We conclude that reef structure is heavily correlated with wave energy and that this forcing function has two effects. Its primary effect produces a zonation of reef structure across the gradient of the transect, through the attenuation of wave energy towards the lagoon. The diagnostic features of this effect are an increasing proportion of sand and a decreasing proportion of most other structural types, both living and nonliving, as the transect passes into the lagoon. The second effect is due to differences in the nature of the function on the 2 sides of the Reef. The exposed northern side is distinguished from all other parts of the transect, including to a degree the southern side, by a preponderance of rubble and a lack of delicate thin branching corals. The sheltered southern side is distinguished from all other parts of the transect by the development of pavement and non-branched corals.

\section{THE CORAL COMMUNITY STRUCTURE}

The major architectural species of Heron Island Reef are the scleractinian corals. They were sampled in a similar way to the substrate types that were used to determine the reef structure. As before, 3 replicate line transects were made at each of the 45 sites. For the corals, however, the line transects were $20 \mathrm{mlong}$ and each sample consisted of a sequence of 100 records of the species recorded at $20 \mathrm{~cm}$ intervals. Each record consisted of the dominant (usually the only) species found inside a $10 \mathrm{~cm}$ circle centred on the sampling point, as before. The larger samples were required to accommodate the greater number of species compared to the number of structural types. A total of 45 species was recorded across the transect and, of these, 39 occurred more than once. These 39 species together with the attribute called 'non-living substrate' were used in the subsequent analyses, the singletons being discarded following the usual practice (Williams et al.,

Table 4. Coral species used for analysis

\begin{tabular}{|rl|}
\hline 1 & Acropora cuneata (Dana) \\
2 & Goniopora tenuidens (Quelche) \\
3 & Pocillopora damicornis (Linnaeus) \\
4 & Stylophora pistillata Esper \\
5 & Favites abdita (Ellis \& Solander) \\
6 & Goniastrea cf. favulus (Dana) \\
7 & Acropora palifera (Lamarck) \\
8 & Seriatopora hystrix Dana \\
9 & Acropora millepora (Ehrenberg) \\
10 & Porites cf. annae Crossland \\
11 & Acropora humilis (Dana) \\
12 & Acropora tubicinaria (Dana) \\
13 & Platygyra sinensis (Edwards \& Haime) \\
14 & Favia pallida (Dana) \\
15 & Leptastrea purpurea (Dana) \\
16 & Montastrea curta (Dana) \\
17 & Acropora hyacinthus (Dana) \\
18 & Acropora austera (Dana) \\
19 & Hydnophora microconos (Lamarck) \\
20 & Montipora uniformis Bernard (rough form) \\
21 & Porites lutea (Edwards \& Haime) \\
22 & Pavona decussata (Dana) \\
23 & Astreopora myriophthalma (Lamarck) \\
24 & Goniastrea retiformis (Lamarck) \\
25 & Leptoria phrygia (Ellis \& Solander) \\
26 & Porites lichen (Dana) \\
27 & Acropora aspera (Dana) \\
28 & Porites andrewsi Vaughan \\
29 & Montipora uniformis Bernard (smooth form) \\
30 & Lobophyllia hemprichii (Ehrenberg) \\
31 & Acrhelia horrescens (Dana) \\
32 & Symphyllia radians Edwards \& Haime \\
33 & Plesiastrea versipora (Lamarck) \\
34 & Acropora cerealis (Dana) \\
35 & Psammocora haimeana Edwards \& Haime \\
36 & Turbinaria heronensis Wells \\
37 & Fungia fungites (Linnaeus) \\
38 & Merulina ampliata (Ellis \& Solander) \\
39 & Echinopora lamellosa (Esper) \\
& \\
\hline
\end{tabular}


1969; Stephenson et al., 1972). The coral species are given in Table. 4.

The 135 samples were classified by the program CENPERC using the 40 attributes above. The replicates showed statistically significant clustering at the 8-group level by the test of Sandland and Young $(1979 a, b)$ and so were pooled as before to expedite further analysis.

Living corals were absent from some of the sites in the lagoon (sites 13,19,20). These sites are not considered further here. The attribute 'non-living substrate' was also excluded from consideration since it does not contribute directly to an understanding of the coral community structure. A total of 42 sites remained, and they were described by the frequency of occurrence of 39 coral species. These sites were then reclassified as for the reef structure by the program CENPERC, a principal co-ordinate analysis made on the intersite dissimilarity matrix and the diagnostic program GOWECOR run on the results of the ordination.

The classification (Fig. 4) extracts the subjective reef zones and also distinguishes between the northern and southern sides of the reef. However the pattern of branching of the dendrogram is not as consistent as we saw with the structure classification. In that analysis, the major splits divided up the transect by zones while subsequent splits divided the zones into their northern and southern representations. Here, the first few splits produce, at the 3-group level, a major group in which northern and southern zones are mixed and 2 other

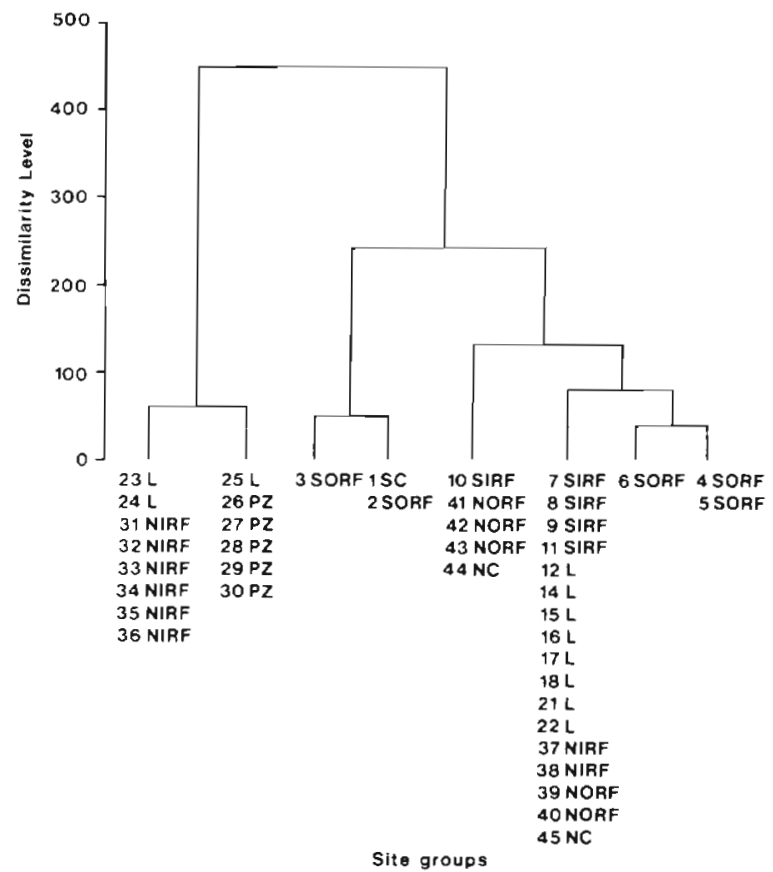

Fig. 4. Classification of coral community. For abbreviations see Table 1 smaller groups, one containing northern, the other southern sites. At the 6-group level, the major group has split to produce 3 groups, 1 of which emphasizes zones, while the other 2 emphasize north/south differences. One of the smaller groups from the 3-group level has now split into 2 zones. This mixture of splits continues so that by the time the 8-group level is reached, the sites are divided more or less clearly both into zones and along north/south lines. However, the route by which this has been achieved is a mixture of the 2 processes.

We conclude from the classification that both the zonation and the north/south differences are effectively recovered, but that these 2 different effects are about equal in importance.

The ordination shows the same mixture of effects. It extracted $89 \%$ of the variance in the first 3 eigenvectors. This high degree of 'explanation' in these few dimensions suggests a well structured community of corals in the study area, and one which should repay detailed analysis, despite its complexity.

The first 3 eigenvectors plotted against the transect
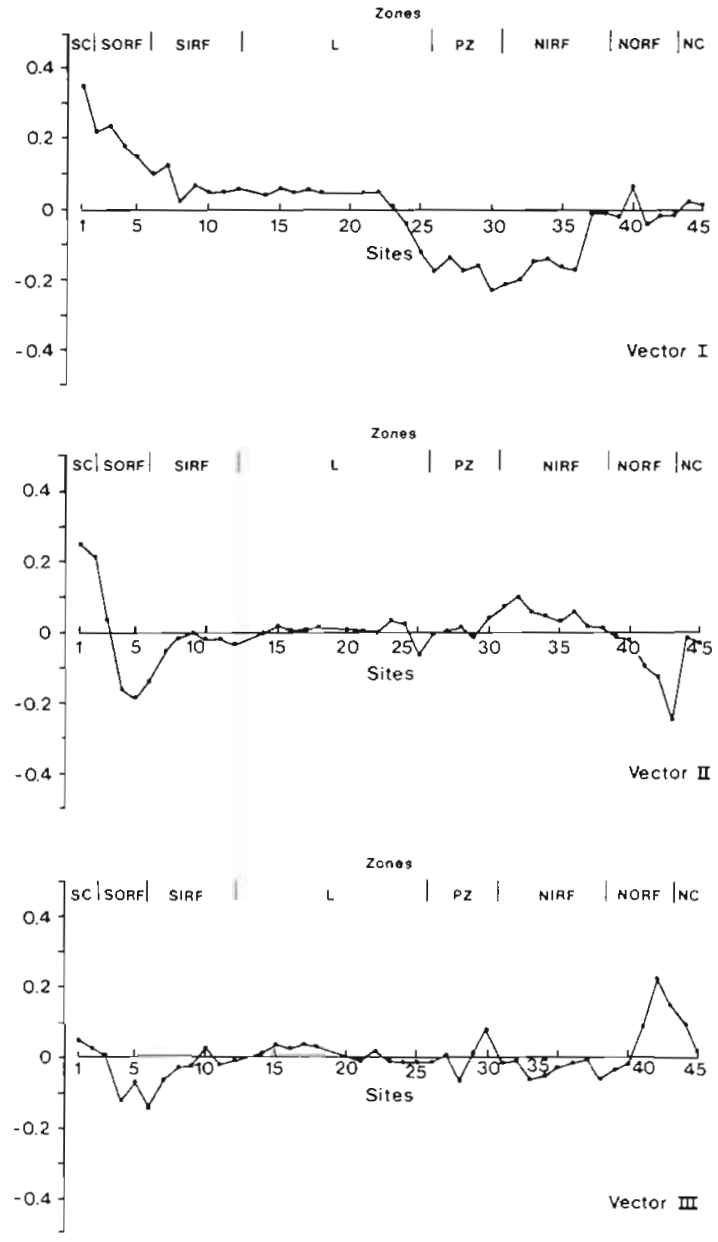

Fig. 5. Coral community structure Vectors I, II and III plotted against transect. For abbreviations see Table 1 
are given in Fig. 5. The component patterns, that together create the zonation patterns seen in the classification, are now clearly dissected.

The first vector, which accounts for $53 \%$ of the variance, shows a steady gradient of dissimilarity from the southern reef crest through to the northern Pocillopora zone and inner reef flat. The north outer reef flat and crest are relatively undifferentiated. This vector simultaneously emphasizes a difference between zones and between north and south sides of the Reef. The second vector ( $24 \%$ of the variance) also distinguishes the southern edge of the Reef (the crest and the outer part of the outer reef flat), but here it distinguishes it from the rest of the south outer reef flat as well as the north outer reef flat. The third vector $(13 \%)$ distinguishes the south outer reef flat and the north inner reef flat from the north outer reef flat.

Thus the ordination has as much difficulty as the classification in separating out the north/south effects from the between-zone effects. However, the ordination shows quite clearly why this is so: the south reef flat and crest dominate the analysis by their complexity. Sites there show several independent ways of differing from the rest of the transect and these ways confound the zone and north/south distinctions. Our simple model of a major forcing function, wave energy, with 2 aspects, attenuation causing zonation and intensity causing north/south difference, needs to be modified. The southern side reflects a non-linear response to wave energy since more than 1 vector is required to describe it. We may conclude from the ordination nevertheless that the north/south effect is the more important.

The GOWECOR analysis reveals the diagnostic attributes for each of the vectors (Table 5), and so allows a more detailed investigation of the responses of the corals. The first vector separates Pocillopora and Porites lichen from Montipora uniformis (smooth form),
Acropora aspera, Acropora millepora and Porites cf. annae to distinguish the northern Pocillopora zone and contiguous inner reef flat from the south reef crest and outer reef flat. The second vector uses the distinction between $A$. millepora and $A$. humilis on the one hand and A. Cuneata, Lobophyllia, A. palifera and Seriatopora on the other to discriminate the southern edge of the Reef from the north outer reef flat and the rest of the south reef flat. The third vector emphasizes Acrhelia, Merulina, Echinopora, Seriatopora and Porites lichen in distinguishing the north outer reef flat from the south reef flat.

We conclude that coral community structure is strongly correlated with wave energy. Both zonation effects (as a correlate of wave energy attenuation) and north/south differences (as a correlate of wave energy intensity) may be seen. They are, however, dominated by a complex non-linear response of the corals to the reduction in wave energy intensity on the southern side of the Reef. This effect has at least 3 independent aspects. The most important is demonstrated by all sites except the north outer reef flat and north crest and is a decline in species richness passing from the south crest to the species-poor Pocillopora dominated areas. The second is the development of an Acropora dominated zone only on the south crest distinguishing it from a zonation of Acropora on both north and south outer reef flats. The third aspect is the presence of corals such as Acrhelia, Merulina, Echinopora and Seriatopora on the scoured moat of the north outer reef flat, replacing the species contributing to the contrast between the south crest and the Pocillopora zone. This replacement is most apparent in the contrast between the exposed north outer reef flat and the sheltered south outer reef flat. The replacement corals are all similar in their distribution patterns suggesting that all may be $r$-strategists as has been shown for Seriatopora by Loya (1976).

Table 5. Diagnostic analysis: coral community structure

\begin{tabular}{|c|c|c|c|c|c|}
\hline \multicolumn{6}{|c|}{ Vector } \\
\hline \multicolumn{2}{|l|}{ I } & \multicolumn{2}{|c|}{ II } & \multicolumn{2}{|l|}{ III } \\
\hline Attribute & $\begin{array}{l}\text { Correlation } \\
\text { coefficient }\end{array}$ & Attribute & $\begin{array}{l}\text { Correlation } \\
\text { coefficient }\end{array}$ & Attribute & $\begin{array}{c}\text { Correlation } \\
\text { coefficient }\end{array}$ \\
\hline Pocillopora & -.80 & A. cuneata & -.59 & Acrhelia & .62 \\
\hline Montipora (Smooth) & .62 & A. millepora & .57 & Merulina & .55 \\
\hline A. aspera & .60 & A. humilis & .56 & Echinopora & .55 \\
\hline A. millepora & .57 & Lobophyllia & -.53 & Seriatopora & .54 \\
\hline Porites cf. annae & .56 & A. palifera & -.51 & Porites lichen & .51 \\
\hline Porites lichen & -.55 & Seriatopora & -.50 & & \\
\hline Favites abdita & .54 & & & & \\
\hline
\end{tabular}




\section{CONGRUENCE OF THE REEF STRUCTURE AND CORAL COMMUNITY STRUCTURE}

The 2 patterns need not necessarily be similar. Some corals exhibit more than 1 shape, some corals converge on the 1 shape and much of the reef structure is composed of non-living material. Thus the patterns are at least potentially independent. However, as we have seen above, there are aspects of both the reef structure and coral community structure which are correlated with the same forcing function, wave energy, so the patterns may well be related. A detailed examination of the congruence of these patterns should provide some insight into the ways in which the effects of forcing function are propagated through this ecosystem.

Classifications are difficult to compare objectively (Clifford, 1976) but ordination patterns may be compared by the multivariate technique of canonical coordinate analysis (Pielou, 1977). This technique, while very powerful, is only suitable when the same number of sites is examined in each of the 2 cases being compared. The 3 sites that contained no living corals were dropped from the coral community ordination resulting in a smaller number of sites than in the reef structure ordination. The 2 sets could be made comparable by deleting the relevant reef structure sites and reanalysing. However, we have preferred the simpler solution of preparing a simple intercorrelation matrix between the vectors from each set, using comparable sites. This is a less elegant solution than canonical coordinate analysis but has the virtues of being easily interpretable and more robust in the sense that, with care, the deleted sites may be allowed for. We will return to this point later.

The intercorrelation matrix between the first 3 vectors of the reef structure ordination and the 3 vectors of the coral community ordination is given in Table 6. It was based on the 42 sites in common.

An examination of this matrix reveals that the correlations are nearly everywhere low. The only correlation that is significant is Coral I versus Reef Structure III at $\mathrm{p}<0.01$. This correlation draws heavily on the characteristics of the south crest and outer reef flat, an area of some complexity as we noted earlier The lack of any other significant correlations demonstrates that the reef structure is largely independent of the coral community structure. Therefore their relationships with the forcing function are substantally independent of each other.

We may conclude from the above that, while the reef structure and coral community structure are each well correlated with the forcing function, wave energy, these relationships are essentially independent of each other.
Table 6. Correlation coefficients: coral community structure vectors vs. reef structure vectors

\begin{tabular}{lrrrr|}
\hline \multicolumn{5}{c}{ Coral community vectors } \\
& & I & II & III \\
\hline Reef & I & -.132 & 107 & .007 \\
Structure & II & .340 & .073 & .277 \\
Vectors & III & .565 & .218 & .087 \\
& & & & \\
- Significant: $\mathrm{p}<0.01, \mathrm{n}=42$ & & \\
\hline
\end{tabular}

\section{THE FISH COMMUNITY STRUCTURE}

The fish community was chosen as a suitable tool for investigating the propagation of the forcing function, wave energy, deeper into the ecosystem. Other studies have shown both the reef structure and coral community structure to be related to the forcing function (Stoddart, 1969; Chappell, 1980), and the fish community to be related to the reef structure and coral community structure (Luckhurst and Luckhurst, 1978; Talbot et al., 1978). The fish community may also be related directly to the forcing function. This part of the study, therefore, was concerned with describing the fish community structure, while the following section is concerned with probing the relationship of that structure with the reef structure and coral community structure.

It was not possible to sample the fish community at all 45 sites on the transect because of the effort involved, any reasonable sample of the fish requiring much more work than coral or substrate samples. Therefore 9 sites (numbers $3,7,10,17,27,33,39,41$, 45) were chosen across the transect as representative of the major zones as revealed by the previous analyses. Paired samples were taken at each of these 9 sites. Each of the 18 samples consisted of the fish retained by a $2 \mathrm{~mm}$ mesh within an area of $21.5 \mathrm{~m}^{2}$ The samples were taken by staking the net out around the area, during which time most of the resident fish retreated into the cover of the coral. The enclosed area was then poisoned and the fish were collected by hand nets until the area was exhausted. A total of 98 species of fish which were recorded more than once in the samples are given in Table 7 .

The 18 samples were classified by the program MULTBET (Milne, 1976) using, as binary attributes, the presence or absence of the 98 fish species. MULT$\mathrm{BET}$ is an agglomerative, polythetic program and is a useful substitute for CENPERC when binary data are being used. The replicates showed statistically significant clustering at the 3-group level by the test of Sandland and Young (1979a, b). The presence of only two replicates at each site considerably reduced the 
Table 7 Fish species used for analysis

Dussumieriidae

1 . Spratelloides robustus Ogilby

Myridae

2 Muraenichthys iredalei Whitley

Soleidae

3 Pardachirus hedleyi Ogilby

Sygnathidae

4 Corythoichthys sp. 1

5 Micrognathus brevirostris (Ruppell)

Apogonidae

6 Apogon doederleini Jordan \& Snyder

7 Apogon nubilis Garman

8 Apogon sp. 1

9 Apogon sp. 2

10 Lovamia cooki (Macleay)

1 Cheilodipterus quinquelineatus Cuvier \& Valenciennes

12 Apogonichthys marmoratus Alleyne \& Macleay

Epinephelidae

13 Epinephelus gilberti (Richardson)

Pseudochromidae

14 Pseudochromis novaehollandiae Steindachner

15 Leptochromis tapeinosoma (Bleeker)

Plesiopidae

16 Plesiops coeruleolineatus Ruppell

17 Plesiops corallicola Bleeker

18 Belanopterygion fasciolatus (Ogilby) Lutjanidae

19 Lutjanus carponotatus (Richardson)

Scolopsidae

20 Scolopsis cancellatus (Cuvier) Gerridae

21 Gerres carinatus Alleyne \& Macleay Chaetodontidae

22 Chaetodon trifasciatus Mungo Park

23 Chaetodontops Iunula (Lacepede)

24 Chelmon rostratus (Linnaeus)

Pomacentridae

25 Pomacentrus wardi Whitley

26 Pomacentrus vaiuli Jordan \& Seale

27 Pomacentrus moluccensis Bleeker

28 Pomacentrus flavicauda Whitley

29 Pomacentrus taeniometopon Bleeker

30 Dascyllus aruanus (Linnaeus)

1 Paraglyphidodon melas (Cuvier)

32 Chromis atripectoralis Welander \& Schultz

33 Acanthochromis polyacanthus (Bleeker)

34 Dischistodus pseudochrysopoecilus (Allen \& Robinson)

Labridae

35 Halichoerus hartzfeldi (Bleeker)

36 Halichoerus trimaculatus (Griffith)

37 Halichoerus margaritaceus (Valenciennes)

38 Halichoerus hoveni (Bleeker)

39 Coris variegata (Ruppell)

40 Stethojulis strigiventer (Bennett)

41 Stethojulis bandanensis (Bleeker)

42 Cheilinus chlorurus (Bleeker)

43 Pseudolabrus guentheri Bleeker

44 Choerodon transversalis Whitley

45 Hemigymnus melapterus (Bloch)

46 Thalassoma lunare (Linnaeus)

Scaridae

47 Scarus sp. 1

48 Scarus sp. 2
Opisthognathidae

49 Opisthognathus eximius (Ogilby)

Parapercidae

50 Parapercis cylindrica (Bloch)

Limnichthyidae

51 Limnichthys fasciatus Whitley

Blenniidae

52 Salarias fasciatus (Bloch)

53 Salarias sinuosus Snyder

54 Petroscirtes mitratus Ruppell

55 Petroscirtes fallax Smith-Vaniz

56 Petroscirtes lupus De Vis

57 Atrosalarias fuscus (Gunther)

58 Enchelyurus kraussi (Klunzinger)

59 Omobrachus rotundiceps (Macleay)

60 Meiacanthus lineatus (De Vis)

61 Escenius mandibularis McCulloch Congrogadidae

62 Blennodesmus scapularis Gunther

63 Congrogadus subducens (Richardson)

Clinidae

64 Clinid sp. 1

65 Clinid sp. 2

66 Clinid sp. 3

67 Clinid sp. 4

Brotulidae

68 Dinematichthys iluocoetoides Bleeker Callionymidae

69 Callionymus rameus McCulloch Siganidae

70 Siganus punctatus (Schneider) Acanthuridae

71 Naso unicornis (Forskal)

72 Acanthurus sp. 1

\section{Gobıidae}

73 Priolepis nuchifasciatus (Gunther)

74 Favonogobius lateralis (Macleay)

75 Fusigobius neophytes (Gunther)

76 Trimma macropthalma (Tomiyama)

77 Amblygobius bynoensis (Richardson)

78 Amblygobius phalaena (Cuvier \& Valenciennes)

79 Istigobius $\mathrm{sp} .1$

80 Gnatholepis sp. 1

81 Bathygobius sp. 1

82 Callogobius sp. 1

83 Paragobiodon lacunicolus (Kendall \& Goldsborough)

84 Paragobiodon xanthosoma (Bleeker)

85 Paragobiodon sp. 1

86 Gobiodon histrio (Valenciennes)

87 Gobiodon heterospilus (Bleeker)

88 Gobiodon sp. 1

89 Valenciennea longipinnis (Lay \& Bennett)

90 Eviota nebulosa Smith

91 Eviota virdis (Waite)

92 Asterropteryx semipunctatus (Ruppell)

93 Asterropteryx sp. 1

Platycephalidae

94 Platycephalus bosschei Bleeker

Scorpaenidae

95 Scorpaenopsis guamensis (Quoy \& Gaimard)

96 Scorpaenopsis gibbosa (Bloch \& Schneider)

97 Dendrochirus zebra (Quoy \& Gaimard)

Gobiesocidae

98 Lepadichthys frenatus Waite 
power of the test, so although only 3 groups of sites were significantly clustered, 6 pairs of replicates fused together prior to any other fusions. Therefore it was considered that they were sufficiently similar that they could be pooled to form 9 samples as in the previous analyses.

The 9 sites were then reclassified by the program CENPERC using the frequencies of the pooled binary data. This was followed by a principal co-ordinate analysis of the intersite dissimilarity matrix and the diagnostic program GOWECOR as before.

The classification (Fig. 6) needs to be interpreted with caution since so few sites are involved. However, the pattern of branching of the dendrogram is instructive. The primary split clearly separates the northern and southern reef sites with the exception of the lagoon and Pocillopora zone which are placed in the northern and southern groups respectively. At the 3-group level, the lagoon and north crest sites are removed from the northern group of sites. This pattern reflects the intensity aspect of the forcing function in that all northern and southern sites except the Pocillopora zone site are first separated. It also indicates a pattern not directly related to the forcing function, since, at the 3-group level, the lagoon and north crest sites form a coherent group. A simple interpretation of this level is that the classification may reflect the distribution of fish refuge sites. If so, at the 3-group level, we have in descending amount of refuges:

(a) Southern reef sites plus Pocillopora zone; (b) northern reef sites except crest; (c) north crest plus lagoon.

We conclude that both a north/south effect and a possible refuge effect are recovered by the classification. A zonation effect is not clear.

The ordination also needs to be interpreted with care. It extracted only $52 \%$ of the variance in the first 3 eigenvectors, suggesting that more than 3 dimensions are needed to accommodate the distribution patterns of the large number of species. It also suggests that, as

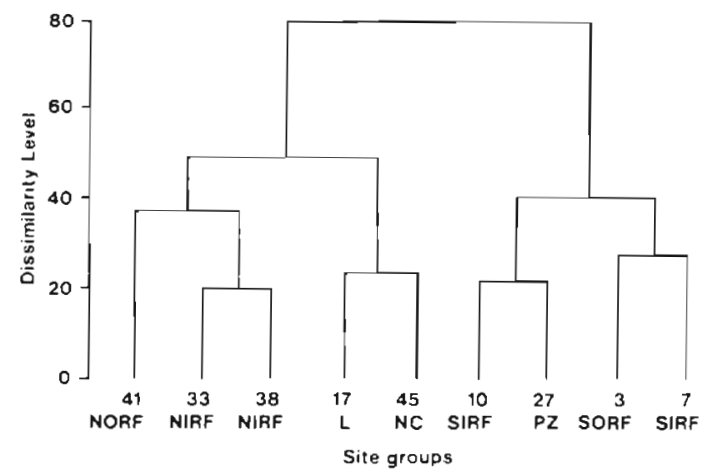

Fig. 6. Classification of fish community. For abbreviatıons see Table 1 well as the apparently simple conformation of the fish to some simple factors as seen be the classification, there may be more subtle patterns.

The eigenvectors were plotted against the transect (Fig. 7) to clarify their trends. The first vector, which explained $24 \%$ of the variance, is high on the south reef flat and Pocillopora zone and falls from these areas to the lagoon and north reef flat and crest. The second vector ( $15 \%$ of the variance) is high on the outer parts of both reef flats and falls to the lagoon and north reef crest. The third vector $(14 \%)$ is high on the north inner reef flat and falls from there both to the north and south across the transect.
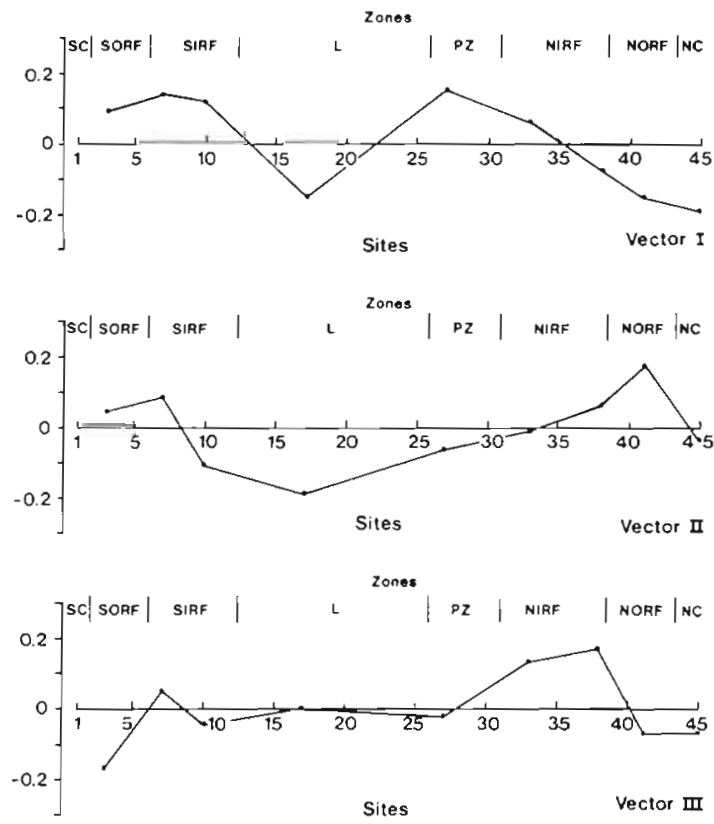

Fig. 7. Fish community structure Vectors I, II and III plotted against transect. For abbreviations see Table 1

The ordination, therefore, is able to dissect the patterns seen in the classification with some precision. The major effect, seen in Vector 1 , is the postulated refuge effect with the south reef flat, Pocillopora zone and contiguous north inner reef flat differentiated from the rest of the sites. This may also be interpreted as an intensity effect of the forcing function in that the northern peak in this vector is 'forced' well back from the crest compared to the southern peak. The second effect may be interpreted as a zonation effect since both north and south sides are behaving similarly. This effect was masked in the classification. The third effect, about equal in importance to the second, recovers a discrete difference between northern inner reef flat sites and the rest of the transect.

The GOWECOR analysis (Table 8 ) reveals the diagnostic features of the ordination. As may be expected, 
the first vector discriminates between the distribution of species associated with live ramose corals (e. g. the pomacentrids and apogonids) and those associated with loose coral rubble (e. g. Halichoerus margaritaceus, Blennodesmus scapularis, Plesiops coeruleolineatus and Bathygobius sp. 1). The former predominate in the Pocillopora zone, south reef flat and north inner reef flat, whereas the latter are found mostly in the lagoon, north crest and north outer reef flat. The second vector, which reflects zonation, was associated with increased frequencies of Halichoerus hartzfeldi, Gerres carinatus and Omobranchus rotundiceps which occurred more often in the Pocillopora zone, north crest and lagoon; whereas Priolepis nuchifasciatus, Leptochromis tapeinosoma; clinid sp. 1, Escenius mandibularis and Muraenichthys iredalei were found in the two outer reef flats and the outer part of the inner reef flats. The third vector discriminates the extremely sheltered north inner reef flat from the rest of the transect. Although most species showed relatively poor correlations with this pattern the best correlated species, such as Micrognathus brevirostris and juvenile Scarus sp. 2 , showed increased frequencies in this area.

We conclude that the fish community structure does not show clear, direct correlations with the forcing function, wave energy. The explanatory power of the individual vectors is not as great as in the previous analyses, suggesting that the patterns in this community are complex. The primary pattern may be equivocally assigned to the intensity effect of wave energy, while the secondary pattern may reflect zonation. However, other effects such as the distribution of refuges and the character of the north inner reef flat intrude on this simple interpretation. The diagnostic features of the patterns may add to, rather than reduce, this complexity because of the great numbers of species involved. Only the diagnosis of the primary pattern is clear and the life histories of these species give weight to the selective refuge effect.

\section{CONGRUENCE OF FISH COMMUNITY STRUCTURE WITH THE REEF STRUCTURE AND CORAL COMMUNITY STRUCTURE}

In order to compare the fish community structure with the other aspects of the ecosystem, we need to create comparable data sets. The previous comparison needed care because a few sites were missing from one side of the comparison. There, we justified deleting the unbalanced sites from the results of the ordination since this procedure discarded the minimum amount of information. Here, the problem is more acute since there are only 9 fish sites. Discarding all the unbalanced sites and reordinating is one solution, but a drastic one, since it discards four-fifths of the information collected on the reef structure and coral community structure. Instead we chose to transform the results of the ordinations of the coral community and reef structures by taking the means, for each vector, of the 3 adjacent sites centred on each fish site. Site 45 was exceptional, and it was replaced with the mean of Sites 43, 44 and 45. These 9 mean values for each reef structure and coral community vector were then used in the comparisons. This strategy is intuitively appealing since it permits much of the information of the nonfish sites to intrude into the comparison

The correlations between each of the first 3 vectors of

Table 8. Diagnostic analysis: fish community structure

\begin{tabular}{|c|c|c|c|c|c|}
\hline \multicolumn{6}{|c|}{ Vector } \\
\hline Attribute & $\begin{array}{l}\text { Correlation } \\
\text { coefficient }\end{array}$ & Attribute & $\begin{array}{l}\text { relation } \\
\text { efficient }\end{array}$ & Attribute & $\begin{array}{l}\text { Correlation } \\
\text { coefficient }\end{array}$ \\
\hline Pomacentrus wardi & .93 & Priolepis nuchifasciatus & 78 & Micrognathus brevirostris & .85 \\
\hline Halichoerus margaritaceus & -.90 & Halichoerus hartzfeldi & -.75 & Scarus sp. 2 & .83 \\
\hline Lovamia cooki & .89 & Leptochromis tapeinosoma & .74 & Clinid sp. 2 & -.64 \\
\hline Apogonichthys marmoratus & .89 & Clinid sp. 1 & .67 & Stethojulis strigiventer & .63 \\
\hline Pomacentrus moluccensis & .89 & Gerres carinatus & -.67 & Clinid sp. 4 & -.62 \\
\hline Atrosalarius fuscus & .89 & Escenius mandibularis & .67 & Asterropteryx semipunctatus & .61 \\
\hline Acanthochromis polyacanthus & .80 & Muraenichthys iredalei & .66 & Choerodon transversalis & .60 \\
\hline Blennodesmus scapularis & -.75 & Omobranchus rotundiceps & -.66 & Amblygobius bynoensis & .60 \\
\hline Scorpaenopsis sebastipistes & .74 & Petroscirtes mitratus & -.64 & Gnatholepis sp. 1 & .60 \\
\hline Dinematichthys iluocoetoides & .72 & Petroscirtes lupus & -.64 & Plesiops corallicola & -.60 \\
\hline Bathygobius sp. 1 & -.69 & Favonogobius lateralis & -.64 & Paraperis cylindrica & .59 \\
\hline Plesiops coeruleolineatus & -.67 & Eviota virdis & .64 & Chromis apectoralis & -.59 \\
\hline Apogon nubilis & .66 & Coris variegata & .63 & Chaetodon trifasciatus & -.59 \\
\hline Cheilodipteris quinquelineatus & .63 & Amblygobius phalaena & -.62 & Pardachirus hedleyi & -.59 \\
\hline
\end{tabular}


Table 9. Correlation coefficients: fish community structure vectors vs. reef structure vectors

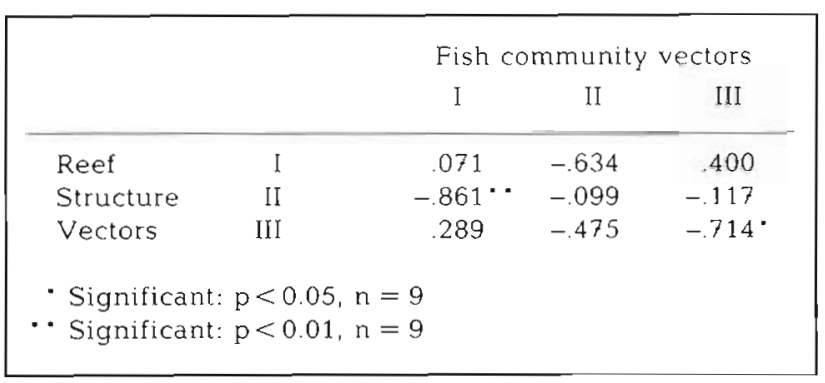

Table 10. Correlation coefficients: fish community structure vectors vs. coral community structure vectors

\begin{tabular}{lrrrr|}
\hline & \multicolumn{4}{c|}{ Fish community vectors } \\
& I & II & III \\
\hline Coral & I & .030 & 103 & -.542 \\
Community & II & .232 & -.440 & -.165 \\
Vectors & III & -.815 & .001 & -.430 \\
- Significant: $\mathrm{p}<0.01, \mathrm{n}=9$ & & \\
\hline
\end{tabular}

the ordination of the fish community and each of the first 3 vectors of the reef structure ordination are given in Table 9, while Table 10 gives the former's correlations with the coral community vectors.

An examination of these tables reveals that the correlations are generally low. There are 3 statistically significant correlations. The first vector is significantly correlated with Reef Structure II $(r=-0.861$, $\mathrm{p}<0.01)$ with Coral III $(r=-0.815, \mathrm{p}<0.01)$. The third fish vector is significantly correlated with Reef Structure III $(r=-0.714, p<0.05)$. When the correlation between Reef Structure II and Coral III is reexamined (Table 6) to see if they themselves are highly correlated, it is seen to be low $(r=0.277)$. This suggests that the aspects of each that are responsible for the correlation with the fish community structure are independent of each other. Nor are these 2 vectors highly correlated with any other vector, precluding a complex chain of relationships. On the other hand, when the other correlations of Reef Structure III are reexamined (Table 6) we notice that this is the one vector that is significantly correlated with a coral community structure vector, Coral I.

Two important relationships therefore emerge from this analysis:

(a) Fish I is significantly and independently correlated with each of Reef Structure II and Coral III;

(b) Fish III is significantly correlated with Reef Structure III which in turn is significantly correlated with Coral I, the only significant correlation between the coral community and reef structures.

\section{DISCUSSION}

The results provide a focus for discussion beyond the details of the structural patterns and correlations which were discussed as they emerged in the analyses. It is the ecological significance of the patterns and their relationships. We need the external information provided by other studies to interpret these results. This information allows us to assign provisional causal links among the patterns. We will accept, in this discussion, that the patterns of reef structure and coral community structure are the result, in part, of wave energy with which they are well, but independently, correlated (cf. Maxwell et al., 1964; Stoddart, 1969; Chappell, 1980). We will also accept that the patterns of fish community structure are, in part, the result of reef structure and coral community structure with which they are well correlated (cf. Gladfelter and Gladfelter, 1978; Luckhurst and Luckhurst, 1978; Talbot et al., 1978). Certainly the relationships found in our research are not at variance with the general thrust of these studies. Our work quantifies the relationships and brings them together in the one theoretical scheme.

The central features of the patterns are:

(a) The reef structure and coral community structure are substantially independent of each other, even though they both respond to the forcing function;

(b) the fish community structure responds to both reef structure and coral community structure in several different ways, but does not respond clearly to the forcing function;

(c) as one moves from parts of the ecosystem that are directly affected by the forcing function to parts indirectly affected, the patterns become baroque.

Reef structure and coral community structure are substantially indepen$\mathrm{dent}$. This is an important result because it suggests that, for the forcing function, there are at least 2 independent modes of entry into the ecosystem. The pattern of reef structure is simple, and is also simply related to wave energy. The diagnostic features of the pattern are dominated by the non-living components of reef structure. This demonstrates that the clearly evident zonation and the subsidiary differences between the 2 sides of the reef are mediated through abiotic processes. The coral community structure on the other hand is seen to be more complex, both in itself and in its relationship to wave energy. Zonation is still present, as are differences between sides of the reef, but neither is simple or unequivocally dominant. The diagnostic features of these patterns reveal the rich biotic responses of the corals underlying this complexity. These phenomena include a high species diversity on the southern side, a distinct Acropora assemblage on the southern side as well as an Acropora zonation, and 
the presence of a suite of possible $r$-strategists on the northern side. When compared to reef structure, coral community structure is only partially explicable in terms of the forcing function and also responds nonlinearly to it.

Fish community structure responds to reef structure and coral community structure, but not directly to the forcing function. The fish community structure does not show simple responses to wave energy but it does show at least 3 independent relationships with the reef structure and coral community structure. The diagnostic features of the fish community structure suggest that these relationships are mediated through phenomena such as refuge sites, which are themselves affected by the forcing function. The fish community structure was more strongly related to the reef structure with its emphasis on abiotic components than the coral community structure.

The patterns become baroque in insulated parts of the ecosystem. Two processes run parallel in these results as we penetrate the ecosystem passing from its physical substrate, through a sessile component to a vagile component. Firstly, the influence of the forcing function becomes attenuated. Secondly, the patterns become richly complex. Thus the reef structure patterns are simple and direct consequences of wave energy, the coral community structure and, to a greater extent, the fish community structure patterns are complex, indirect and non-linear consequences of wave energy.

We may conclude that the study shows unequivocally that the forcing function, wave energy, propagates through the ecosystem, entering it in at least 2 independent ways. However, as the function penetrates the system it becomes attenuated and its effects become baroque.

Acknowledgements. P. Moran and V Wadley assisted in the collection of data. The Heron Island Research Station provided laboratory facilities during the field work.

\section{LITERATURE CITED}

Chappell, J. (1980). Coral morphology, diversity and reef growth. Nature, Lond. 286: 249-252

Clifford, H. T (1976). Dendrograms and their interpretation. In: Williams, W. T (ed.) Pattern analysis in agricultural science. CSIRO, Melbourne, pp. 96-101
Flood, P. G. (1974). Sand movements on Heron Island - a vegetated sand cay, Great Barrier Reef Province, Australia. In: Cameron, A. M. et al (eds) Proceedings of Second International Coral Reef Symposuum, Vol. 2. Great Barrier Reef Committee, Brıbane, pp. 387-394

Gladfelter, W B., Gladfelter, E. H. (1978). Fish community structure as a function of habitat structure on West lndian patch reefs. Rev. Biol. Trop. 26 (Suppl. 1): 65-84

Grassle, J. F. (1973). Variety in coral reef communitıes. In: Jones, O. A., Endean, R. (eds) Biology and geology of coral reefs, Vol. II, Biology 1. Academic Press, New York, pp. $247-270$

Loya, Y (1976). The Red Sea coral Stylophora pistillata is an $r$ strategist. Nature, Lond. 259: 478-480

Loya, Y (1978). Plotless and transect methods. In: Stoddart, D R., Johannes, R. E. (eds) Coral reefs: research methods UNESCO, Paris, pp. 197-217

Luckhurst, B. E., Luckhurst, K. (1978). Analysis of the influence of substrate variables on coral reef fish communities. Mar. Biol. 49: 317-323

Maxwell, W. G. H., Jell, J. S., McKellar, R. G. (1964). Differentiation of carbonate sediments in the Heron Island Reef. $J$. sediment. Petrol. 34: 294-308

Mergner, H., Scheer, G. (1974). The physiographic zonation and the ecological conditions of some south Indian and Ceylon coral reefs. In: Cameron, A. M. et al. (eds) Proceed. ing of Second International Coral Reef Symposium, Vol. 2. Great Barrier Reef Committee, Brisbane, pp. 3-30

Milne, P. W. (1976). The Canberra programs and therr accession. In: Williams, $W \mathrm{~T}$ (ed.) Pattern analysis in agricultural science. CSIRO, Melbourne, pp. 116-123

Pichon, M. (1978). Recherches sur les peuplements a dominance d'anthozoaires dans les recifs coralliens de Tulear (Madagascar). Atoll Res. Bull. 222: 1-447

Pielou, E. C (1977). Mathematical ecology, Wiley-Interscience, New York

Rosen, B. R. (1971). Principal features of reef coral ecology in shallow water environments of Mahe, Seychelles. Symp. 2ool. Soc. Lond. 28: 163-183

Sandland, R. L., Young, P. C. (1979a). Probabalistic tests and stopping rules associated with hierarchical classification techniques. Aust. J. Ecol. 4: 399-406

Sandland, R. L., Young, P. C. (1979b). Tables of probabilıties associates with the fission of replicate samples in classifications. CSIRO Division of Fisheries and Oceanography Report 108

Stephenson, W., Williams, W. T., Cook, S. D. (1972). Computer analyses of Petersen's original data on bottom communities. Ecol Monogr 42: 387-415

Stoddart, D. R. (1969). Ecology and morphology of recent coral reefs. Biol. Rev. 44: 433-498

Talbot, F. H., Russell, B. C., Anderson, G. V. (1978). Coral reef fish communities: Unstable, high diversity systems? Ecol. Monogr 48: 425-440

Williams, W T., Lance, G. N., Webb, L. J., Tracey, J. G., Connell, J. H. (1969). Studies in the numerical analysis of complex rain-forest communities. IV A method for the elucidation of small-scale forest pattern. J. Ecol. 57: $635-654$ 